\title{
Stage IVA Rectal Cancer AJCC v7
}

National Cancer Institute

\section{Source}

National Cancer Institute. Stage IVA Rectal Cancer A/CC v7. NCI Thesaurus. Code C115055.

Stage IVA includes: Any T, Any N, M1a. M1a: Metastasis confined to one organ or site (e.g., liver, lung, ovary, nonregional node). (AJCC 7th ed.) 